\title{
Towards Future BIM Technology Innovations: A Bibliometric Analysis of the Literature
}

\author{
Ali Khudhair ${ }^{1, *}$, Haijiang $\mathrm{Li}^{1, *}$, Guoqian Ren ${ }^{1, *}$ and Song Liu ${ }^{2}$ \\ 1 BIM for Smart Engineering Center, Cardiff University, Queen's Buildings, Cardiff CF24 3AA, Wales, UK \\ 2 CCCC Second Harbor Consultants Co., Ltd., Wuhan 430040, China; LiuSong@ctesi.com.cn \\ * Correspondence: khudhairAS@cardiff.ac.uk (A.K.); lih@cardiff.ac.uk (H.L.); Reng@cardiff.ac.uk (G.R.)
}

check for

updates

Citation: Khudhair, A.; Li, H.; Ren,

G.; Liu, S. Towards Future BIM

Technology Innovations: A

Bibliometric Analysis of the

Literature. Appl. Sci. 2021, 11, 1232.

https://doi.org/10.3390/app11031232

Received: 30 December 2020

Accepted: 26 January 2021

Published: 29 January 2021

Publisher's Note: MDPI stays neutral with regard to jurisdictional claims in published maps and institutional affiliations.

Copyright: (c) 2021 by the authors. Licensee MDPI, Basel, Switzerland. This article is an open access article distributed under the terms and conditions of the Creative Commons Attribution (CC BY) license (https:/ creativecommons.org/licenses/by/ $4.0 /)$

\begin{abstract}
The evolution of the construction industry is associated with the continuous implementation of new technologies. Building Information Modelling (BIM) has revolutionised the collaboration and data sharing processes in the architecture, engineering, and construction (AEC) industry. However, it needs to be supported by new technologies that can embrace digital construction by transforming the construction industry into a dynamic environment. There is a lack of understanding of the cutting-edge technologies that have emerged to help with the digital transformation of the construction industry. There is a need to understand all these technologies and how they can be leveraged holistically towards future BIM innovations. Therefore, this article conducts a literature review to evaluate how targeted cutting-edge technologies can be utilised to release the full potential of BIM from a technical perspective. A bibliometric analysis focusing on the co-occurrence of keywords related to various technologies, their links with BIM, and their related research themes was conducted based on the Web of Science (WoS) database holdings from 2010 to 2019. The findings demonstrate that one type of technology can help with solving a specific issue. However, using one technology alone does not solve an issue entirely. The current technology has been utilised independently and not as a coherent system. Thus, a weak information integration and management approach can restrict the leveraging of a smart BIM environment. This paper is not meant to be exclusive. Many new technologies, concepts, and ideas can be added to help realise BIM potentials that are not covered in this study. Furthermore, the analysis was based on the dataset retrieved from WoS and only included the literature in English. Based on those findings, the authors indicated a technology fusion to support BIM development.
\end{abstract}

Keywords: Building Information Modelling (BIM); technologies; bibliometric analysis

\section{Introduction}

The construction industry is changing its regular business methods, with information now being exchanged digitally rather than in paper form. However, the transformation is slow and currently facing many barriers. The evolution of the construction industry is associated with the continuous implementation of new technologies. BIM has added significant value in the development process of the construction industry. It is seen to be a primary asset of information exchange among various stakeholders in the AEC industry [1]. For instance, BIM has the potential to examine how a building is deteriorating over time, which can help in setting up an appropriate strategy for maintenance work [2]. However, it is still not fully employed in the late design stages $[3,4]$. Thus, there is a lack of comprehensive understanding of what BIM should look like in the future.

In any construction project, a significant volume of data, which can be vital, is left out without taking advantage of its unrevealed value. The construction sector needs to understand the importance of this overlooked information since mining and management of an enormous amount of data are critical for better decision-making in future construction projects. It becomes a matter of quality over quantity and how that is affecting the 
decision-making process; in particular, nongeometric information becomes more crucial than geometric information. Although BIM helps manage the information generated, it needs to be coupled with new technologies that can embrace digital construction by transforming the construction industry into a dynamic environment. However, there is still a lack of comprehensive understanding of the potential of the existing technologies and how they can be leveraged holistically towards future BIM.

Technology advancement and engagement in the construction industry has changed over the last decade. Technologies such as artificial intelligence (AI), cloud computing (CC), ontology, blockchain (BC), data analytics (DA), Internet of Things (IoT), laser scanning (LS), and machine learning (ML) have brought tremendous benefits to the construction environment. According to Digital Built Britain [5], which represents the next stage of the United Kingdom digital construction revolution, BIM has excellent potential to be combined with the IoT and DA, which can result in better infrastructure and improve the utilisation of the facilities. Moreover, the concept of a digital twin has been around for several years, which is based on having a virtual model that simulates the existing situations of the real model [6]. This concept obtains real-time data using devices such as sensors that are enabled by technologies such as ML and AI. Bearing in mind that ML is a subset of AI. However, digital twin still requires a framework to follow. BIM, which is a combination of policies, processes, and technologies [7], can support digital twins by being represented as a digital data management platform that can form the starting point for digital twins. Therefore, despite concerns about how BIM can handle various semantic information, it shows that BIM and digital twins can complement each other. LS also plays a role in closing the gap between as-is BIM and as-built BIM, which helps with linking up late lifecycle stages to the design stage. Hence, previous technologies are an important topic and require further investigation. Furthermore, technologies such as ontology and CC have shown their potential to overcome semantic issues [8] and improve collaboration [9] within BIM, respectively. However, using the Internet as a platform for exchanging data among several team members can raise a major issue, which is security. Security has been identified as an important topic within BIM [10]. In recent years, BC has been introduced to the research community to overcome the security issues with BIM. However, most of the research that was conducted on this topic was either conceptual [11], a survey [12], or a literature review [13]. Hence, it is currently a hot research topic.

To achieve a cohesive environment that can bring together different stages in the building lifecycle, BIM entails the utilisation of new technologies. Merging technologies with BIM can result in a robust decision-making framework. However, most of these technologies are not fully embraced by the construction industry yet. The acknowledgement of these technologies has been slow due to the fact that the participants still lack knowledge of these technologies and are unsure whether these technologies will have a negative or positive impact on the project. There is still a lack of understanding on how these technologies are linked to BIM. Furthermore, [14] pointed out that the lack of knowledge about BIM capabilities is constraining the use of BIM, which further explains the need for conducting this research to deliver a comprehensive understanding of what BIM should look like in the future.

Many technologies, concepts, and ideas can be added to help realise BIM potentials. However, this paper is not meant to be exclusive. Further research needs to be integrated in the future. Therefore, this study aims to provide a review of publications to identify the association between the above technologies and BIM and how they can contribute to future BIM development from a technical perspective. In order to address this aim, a bibliometric analysis focusing on the co-occurrence of keywords related to various technologies, their links with BIM, and their related research themes was presented, based on WoS database papers from 2010 to 2019. From the analysis, the authors indicated a technology fusion to support BIM development. The paper is structured as follows: Section 2 provides a background on BIM and the bibliometric analysis of BIM research. The methodology is 
explained in Section 3; Section 4 provides the bibliometric analysis, followed by a discussion is in Section 5. Finally, the conclusions are given in Section 6.

\section{Background}

\subsection{The Benefits and Limitations of BIM in the AEC Industry}

$B I M$ can be characterised as a depot for various information and knowledge, which can be essential for project success and valuable throughout a project's lifecycle $[1,15,16]$, especially because various stakeholders require different information to be exchanged in a project [17]. However, BIM is mostly used in the design and preconstruction stage, and less used in further stages of the building lifecycle [3,4]. The complexity of an asset necessitates adopting new technologies or tools to help manage all this information within BIM and take a further step to realise the full potential of BIM [18].

BIM has brought several advantages to the AEC industry. For instance, it can help with enhancing collaboration on a project by bringing stakeholders closer together and supplying them with visualisation functionalities [14]. Consequently, it helps with synchronising the design and construction plans and detecting design errors [16]. If utilised in an appropriate manner, it can influence numerous aspects such as cost estimation, schedules, compliance checking, design analysis, and environmental and thermal performance $[1,15,19]$. However, there are still several challenges facing BIM in the AEC industry. For instance, interoperability and integration have been acknowledged as important issues in BIM due to the existence of heterogeneous tools and systems [14,20]. Being unable to exchange data seamlessly limits collaboration in the AEC industry, which affects BIM adoption. Moreover, the cost of BIM software tools is one of the factors limiting the application of BIM [14]. Sun et al. [14] also pointed out other factors such as BIM model ownership, model accessibility, data management issues, and data isolation, not to mention the security issues within BIM [10]. There is a necessity to overcome the limitations within BIM since the usage of BIM has become mandatory in some countries. The blend of new technologies in the construction field can help resolve several limitations that restrict BIM adoption in the AEC industry. However, this can take several years to accomplish. There is still a lack of comprehensive understanding on how these technologies are linked to BIM and how they can be leveraged holistically towards future BIM innovations. The possibility of more than one technology working collectively with BIM is close to realisation, but remains a crucial topic for investigation.

\subsection{Bibliometric Analysis of BIM Research}

Exploring field knowledge is an excellent approach to discover gaps and point out the most vital research areas. To evaluate the advancements and research areas in the construction industry, Oraee et al. [21] recommended bibliometric analysis for targeting specific areas of the construction industry. Bibliometric analysis is a document analysis method that is applied to determine the topics related to a field based on the profiles, relationships, and clusters in the research [22].

Many bibliometric analyses on BIM literature have been published in the last three years, which shows that there is great interest in the research field in expanding on BIM. Starting in 2017, Li et al. [23] provided a logical and precise review of BIM knowledge and proposed a BIM knowledge map founded on a knowledge base, domains, and evolution. They endorsed future periodic studies utilising such analysis to improve the BIM knowledge map. Moreover, He et al. [24] conducted a systematic and quantitative review covering only the managerial areas of BIM. The findings of He et al. [24] led to proposing an integrated conceptual framework to structure the future direction of these areas. In addition, Oraee et al. [25] carried out a bibliometric analysis to assess the existing literature on collaboration in BIM-based construction networks. Consequently, this led to the suggestion of a collaboration pentagon as a comprehensive analysis tool for studies on BIM collaboration. Furthermore, Oraee et al. [26] presented another bibliometric analysis of the body of knowledge issued in the proceedings of the Construction Research Congress. 
However, this was a wide-ranging study and not specifically about BIM. Nevertheless, Oraee et al. [26] indicated the prominence of BIM and its abilities to enhance and boost construction processes.

Moreover, Zhao [27] carried out a bibliometric analysis on BIM research wherein he acknowledged that BIM study has predominantly concentrated on categories of engineering, civil engineering, architecture, and construction and building technology along with current emerging categories such as management and sustainability. Furthermore, Zhao [27] identified the hot topics of BIM research, e.g., CC, LS, and Ontology. On the other hand, Santos et al. [28] showed a systematic analysis of all research on BIM and a review of the leading publications. They emphasised the innovative expanding in BIM research field, and found that topics related to BIM tools, BIM adoption, energy simulation, interoperability, and ontology are the standout subjects in BIM research. Finally, Hosseini et al. [29] followed a quantifiable method to investigate the body of BIM knowledge, whereby 45 distinct themes that are closely associated with BIM were recognised. However, the results showed disintegration of the BIM body. Although some of the above papers have discussed technologies such as Ontology, CC, and LS, these technologies were not the main focus of the papers.

\section{Methodology}

Hosseini et al. [29] argued for the necessity of shifting attention from disparate studies to more precise reviews of BIM literature. Hence, this article aims to identify which technologies are excellent candidates to function along with BIM. Currently, there is no thorough investigation concentrating on understanding how certain cutting-edge technologies are complementing BIM to realise its full potential and whether there is any likelihood of fusing more than one technology to support BIM. The research can cover a wide range of topics and involves many technologies. However, this paper is not meant to be exclusive. To restrict the scope of this article, eight research topics have been chosen: AI, CC, Ontology, BC, DA, IoT, LS, and ML. These technologies have the potential to help with the usage of BIM during the whole lifecycle of a building, which in turn can assist with taking a further step to reach BIM's full potential. Further discussion of these technologies, their links with $\mathrm{BIM}$, and the related research will be presented in this paper.

This article methodology, as illustrated in Figure 1, comprises five main stages: paper retrieval (stage 1), which include the initial total number of articles retrieved, followed by the removal of irrelevant publications, which includes two stages ( 2 and 3$)$, where only specific types of publications and the relevant categories are selected, respectively. In stage 4, a bibliometric analysis is conducted, followed by a discussion (stage 5). Further details of these stages are as followings:

1. Paper Retrieval. The literature exploration was performed on WoS database since it has more than 71 million records and over 10 million conference papers. The search was based on keywords using the OR and AND operators search benchmark. For instance, ((BIM OR Building Information Modelling) AND ((artificial intelligence OR AI) OR (cloud computing) OR (ontology) OR (blockchain) OR (data analytics OR DA) OR (internet of things OR IoT) OR (laser scanning) OR (machine learning))). The research involves an analysis of articles issued from 2010 to 2019 (ending on 2nd May). The result of the first stage was 4788 research publications. 


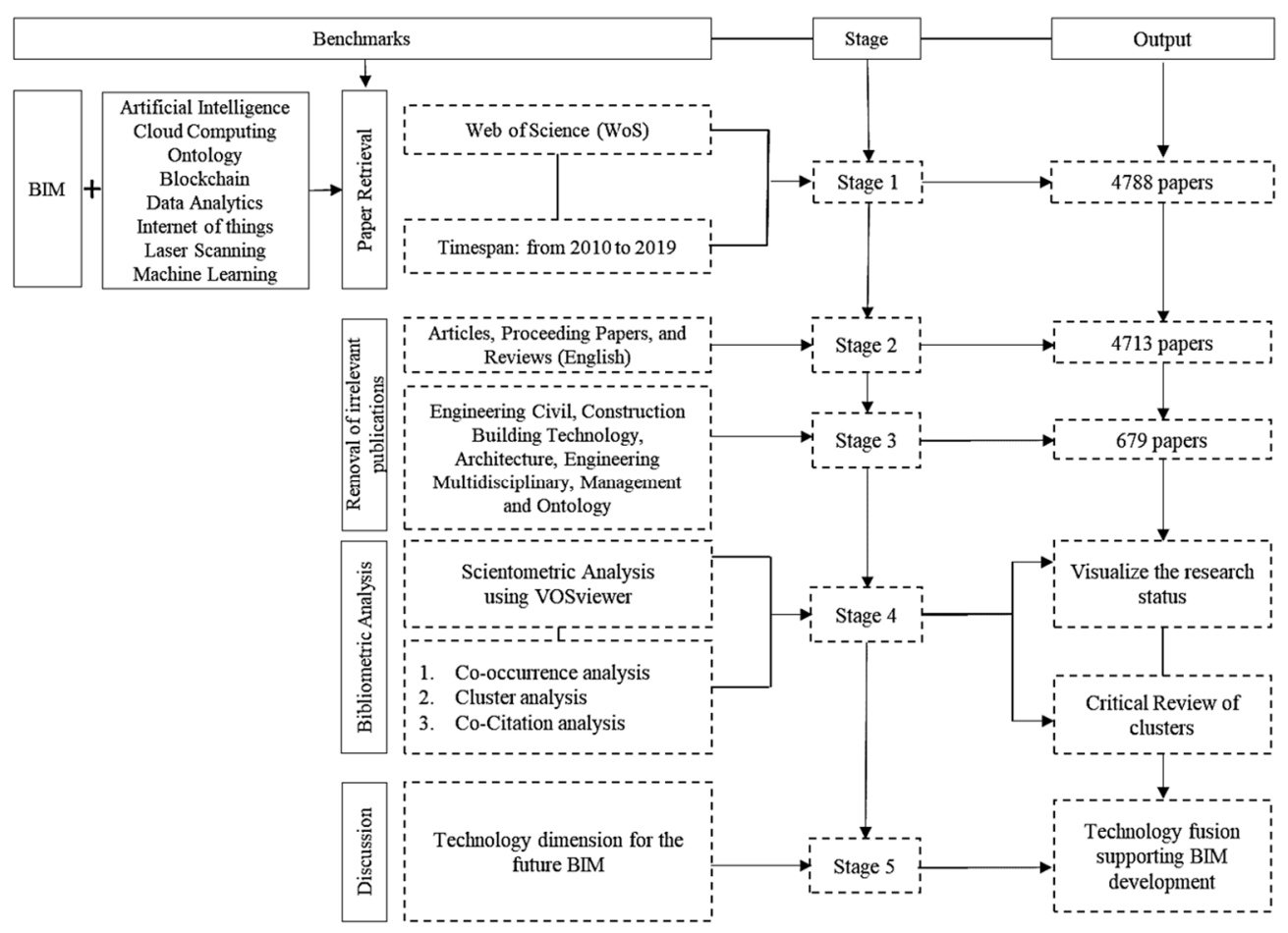

Figure 1. Research methodology.

2. Removal of irrelevant publications (stage 2). The aim behind refining the search is to remove a large amount of irrelevant data that might not contribute to this study. The collected papers were based on the available articles, proceedings, and reviews since these sorts of documents can provide a comprehensive view of the existing research [27]. Furthermore, only publications in English were collected since VOSviewer ${ }^{\circledR}$ [30], which is a software tool established by the Centre for Science and Technology Studies at Leiden University that is used for the analysis of scientometric data, supports only English documents. A total of 4713 papers were identified.

3. Removal of irrelevant publications (stage 3). New groups were selected for this article, besides the ones identified by [27], such as multidisciplinary engineering, management, and ontology. The final literature volume was 679 papers. In the WoS database, bibliographic data can be downloaded for at most 500 publications at a time. Thus, the documents were retrieved in two files. For each publication, the full record, including cited references, was obtained by using the "tab-delimited format" that is supported by VOSviewer ${ }^{\circledR}$.

4. Bibliometric Analysis. Due to the enormous expansion in research, it is challenging to analyse papers manually. Hence, the VOSviewer ${ }^{\circledR}$ was utilised as the analysis tool in this study, and a common quantitative and qualitative method was used to categorise and evaluate the literature. The software supports distance-based maps and allows the user to choose the type of analysis. Five types of analysis exist in this software, coauthorship analysis, co-occurrence analysis, citation analysis, bibliographic coupling analysis, and co-citation analysis. Each of these can be used to deliver a specific need and focus. However, in this study, the focus is to identify the association between the existing technologies and BIM. Hence, co-occurrence analysis and co-citation analysis have been selected as the main focus of this study since they make a major contribution to the aim of this paper. However, further types of analysis such as citation analysis can be integrated in future research. First, Co-occurrence analysis, which is centred on the study of keywords, is used to analyse the word co-occurrence in at least two different articles [23]. The connections between keywords are based on how many times keywords are used together in documents [31]. Based on the 
keywords identified in the co-occurrence analysis, a cluster analysis was conducted to determine the research themes (Section 4.2). Secondly, co-citation analysis, which finds journals that are frequently co-cited together, is selected. If two papers are frequently cited together, it implies that they are interconnected or contribute to the same concepts [31]. Co-citation analysis is divided into three units of analysis: sources, documents, and authors. However, the focus of this study is on the documents unit of analysis to review the existing technologies.

5. Discussion. In order to provide thorough insight into the correlation between cuttingedge technologies and BIM and how they can impact future BIM, this stage includes a discussion followed by the suggestion of technology fusion to support BIM development.

\section{Bibliometric Analysis}

Instead of conducting only a quantitative analysis of publications, a qualitative discussion of the collected papers was considered (Section 4.2). The VOSViewer ${ }^{\circledR}$ supports two counting methods, the fractional counting method and the full counting method. The counting method used in this section and in the rest of the article is the fractional counting method since it is more convenient to avoid single terms that appear often in one document [31].

\subsection{Co-Occurrence Analysis}

The co-occurrence analysis is utilised to provide the main keywords of the collected articles and is based on three units of analysis. However, in this study, the "all keywords" unit of analysis is considered. The following settings have been applied in VOSViewer ${ }^{\circledR}$ tool: The minimum number of occurrences of a keyword was set to 12 . The results indicated that 51 out of 2911 keywords met this threshold. Moreover, a manual normalisation was used to eliminate spelling errors and word repetition to ensure the consistency of the analysis. The final number of keywords was 38, as illustrated in Table 1 and Figure 2. Table 1 reviews the quantitative dimensions of the revealed keywords, which consist of the average publication year, the average citations, and the average normalised citation. The co-occurrence network of keywords generated from the final number of keywords is illustrated in Figure 2. The larger the number of abstracts and titles that have the same two terms in common, the closer these terms to appear in the map [31]. The tool divided the keywords into five clusters, as illustrated in Table 2, of which four out of five will be discussed later in this article (Section 4.2).

Table 1. The quantitative dimensions of the discovered keywords.

\begin{tabular}{|c|c|c|c|c|c|c|}
\hline Keywords & Occurrences & Percentage (\%) & $\begin{array}{c}\text { Total Link } \\
\text { Strength }\end{array}$ & Avg. Pub. Year & Avg. Citation & $\begin{array}{c}\text { Avg. Norm } \\
\text { Citation }\end{array}$ \\
\hline BIM & 137 & 11.77 & 120 & 2016 & 8 & 1.09 \\
\hline ontology & 106 & 9.11 & 89 & 2015 & 9 & 0.92 \\
\hline management & 65 & 5.58 & 62 & 2016 & 12 & 1.69 \\
\hline model & 57 & 4.90 & 48 & 2016 & 14 & 1.44 \\
\hline system & 56 & 4.82 & 54 & 2016 & 13 & 1.47 \\
\hline Construction & 55 & 4.72 & 54 & 2015 & 25.5 & 1.98 \\
\hline design & 42 & 3.61 & 39 & 2015 & 14 & 1.42 \\
\hline Laser scanning & 37 & 3.18 & 35 & 2014 & 19 & 1.25 \\
\hline framework & 36 & 3.09 & 37 & 2016 & 10 & 2.00 \\
\hline Knowledge management & 18 & 1.55 & 15 & 2015 & 10 & 1.26 \\
\hline performance & 33 & 2.83 & 27 & 2016 & 13 & 2.04 \\
\hline buildings & 18 & 1.55 & 15 & 2015 & 13 & 1.46 \\
\hline safety & 12 & 1.03 & 12 & 2016 & 12 & 1.84 \\
\hline recognition & 15 & 1.28 & 14 & 2015 & 28 & 1.92 \\
\hline photogrammetry & 14 & 1.20 & 8 & 2015 & 26 & 1.77 \\
\hline reconstruction & 21 & 1.81 & 18 & 2016 & 25 & 1.93 \\
\hline visualization & 21 & 1.81 & 18 & 2015 & 22 & 2.58 \\
\hline interoperability & 21 & 1.81 & 19 & 2015 & 17 & 1.70 \\
\hline infrastructure & 12 & 1.03 & 11 & 2015 & 16 & 1.25 \\
\hline prediction & 13 & 1.12 & 11 & 2016 & 16 & 1.25 \\
\hline
\end{tabular}


Table 1. Cont.

\begin{tabular}{|c|c|c|c|c|c|c|}
\hline Keywords & Occurrences & Percentage (\%) & $\begin{array}{c}\text { Total Link } \\
\text { Strength }\end{array}$ & Avg. Pub. Year & Avg. Citation & $\begin{array}{c}\text { Avg. Norm } \\
\text { Citation }\end{array}$ \\
\hline point clouds & 22 & 1.89 & 22 & 2015 & 12 & 1.34 \\
\hline cloud computing & 36 & 3.09 & 16 & 2014 & 11 & 1.14 \\
\hline classification & 23 & 1.97 & 18 & 2016 & 10 & 1.02 \\
\hline simulation & 27 & 2.32 & 24 & 2016 & 10 & 1.58 \\
\hline integration & 15 & 1.28 & 14 & 2016 & 10 & 1.42 \\
\hline semantic web & 21 & 1.81 & 20 & 2016 & 9.5 & 1.35 \\
\hline knowledge & 21 & 1.81 & 19 & 2016 & 9 & 1.04 \\
\hline linked data & 12 & 1.03 & 12 & 2016 & 8 & 1.38 \\
\hline algorithm & 12 & 1.03 & 9 & 2015 & 7.6 & 0.92 \\
\hline machine learning & 36 & 3.09 & 25 & 2017 & 8 & 1.34 \\
\hline information & 36 & 3.09 & 32 & 2016 & 7 & 1.45 \\
\hline technology & 18 & 1.55 & 16 & 2016 & 7 & 1.18 \\
\hline optimization & 17 & 1.46 & 16 & 2016 & 5 & 0.76 \\
\hline architecture & 13 & 1.12 & 10 & 2015 & 5 & 0.62 \\
\hline internet of things & 20 & 1.72 & 15 & 2017 & 4 & 1.12 \\
\hline artificial intelligence & 16 & 1.37 & 7 & 2014 & 3 & 0.20 \\
\hline internet & 12 & 1.03 & 11 & 2017 & 3 & 1.50 \\
\hline big data & 17 & 1.46 & 12 & 2017 & 2 & 1.12 \\
\hline
\end{tabular}

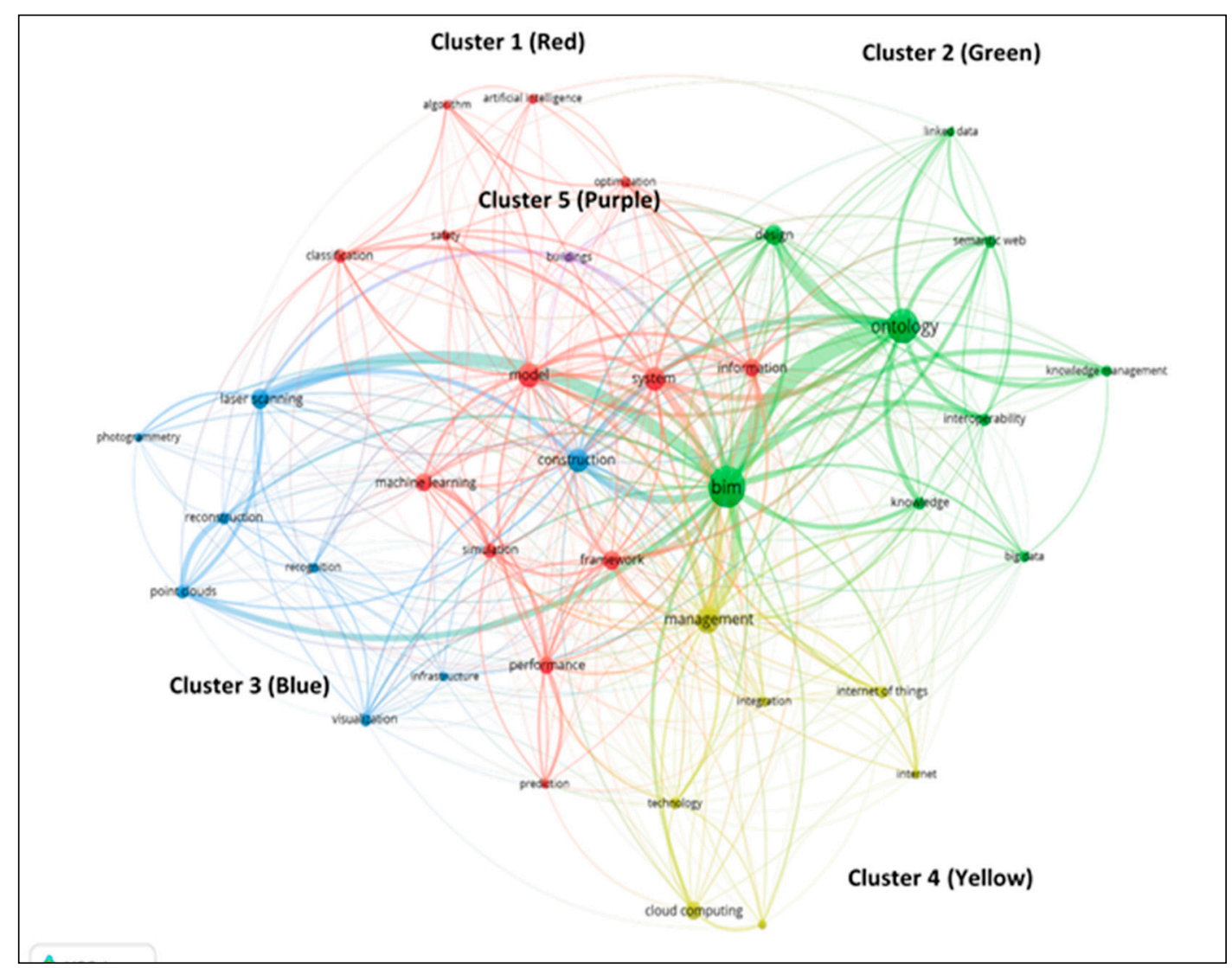

Figure 2. Network visualisation of keywords' co-occurrence.

The average publication year has been examined to detect the recentness of a keyword. For instance, keywords focusing on LS, CC, and AI were published around 2014, which suggests that was when the research community discovered the value and necessity of these technologies to boost the construction industry. Keywords related to interoperability, infrastructure, knowledge management, design, construction, and ontology with a significant appearance of keywords related to LS such as recognition, photogrammetry, and point clouds were circulated in 2015. In 2016, several themes emerged, such as management, performance, safety, reconstruction, prediction, semantic web, knowledge, and optimisa- 
tion. Moreover, in more recent years, themes such as big data, IoTs, and ML have caught researchers' attention. The average publication year gives an idea of the expansion of mindsets in the research community. For instance, the research field has expanded from focusing on new buildings to focusing on new technologies to create BIM models for existing buildings and topics related to various infrastructures. Moreover, more attention has been given to issues of data exchange and how information can be converted into knowledge.

The following keywords have a high average citation: construction (25.5), laser scanning (19), recognition (28), photogrammetry (26), reconstruction (25), visualisation (22), interoperability (17), infrastructure (16), and prediction (16), which shows that there is a significant research focus on existing buildings, 3D rendering and visualisation, and the exchange of heterogeneous information between different stakeholders. In contrast, keywords such as big data (2), artificial intelligence (3), the Internet of things (4), optimisation (5), machine learning (8), linked data (8), simulation (10), cloud computing (11), safety (12), and ontology (9) received a lower average number of citations, which indicates that numerous technologies are yet not completely taken into consideration. For instance, technologies such as AI and ML can play an important role for big data, which represents large sets of structured and non-structured data, especially that many companies rely on big data analytics to discover the areas where they need to improve. Furthermore, the average number of normalised citations indicates which keyword has developed a higher yearly impact in the research area (Table 1). Scores below 1 indicate a low impact, whereas ratings above 1 indicate a higher impact. Because of the settings used in the VOSviewer ${ }^{\circledR}$ tool, and the limited number of articles on topics such BC, the results in Tables 1 and 2 did not show this technology. However, since a combination of the qualitative and quantitative approach is used, this topic will be discussed later in this paper. Most of these technologies can help with extracting and managing the vast amount of data generated in a project and can be correlated to the concept of digital twins. The construction sector needs to understand the importance of these technologies and how they can be leveraged since they can form the tools required to provide a better decision-making framework for future construction projects.

Table 2. Clusters classification based on VOSViewer ${ }^{\circledR}$.

\begin{tabular}{|c|c|c|c|c|c|}
\hline No. & 1 & 2 & 3 & 4 & 5 \\
\hline Items per cluster & 13 & 9 & 8 & 7 & 1 \\
\hline Keywords & $\begin{array}{c}\text { Algorithm } \\
\text { Artificial intelligence } \\
\text { Classification } \\
\text { Framework } \\
\text { Information } \\
\text { Machine learning } \\
\text { Model } \\
\text { optimisation } \\
\text { Performance } \\
\text { Prediction } \\
\text { Safety } \\
\text { Simulation } \\
\text { system }\end{array}$ & $\begin{array}{c} \\
\text { Big data } \\
\text { BIM } \\
\text { Design } \\
\text { Interoperability } \\
\text { Knowledge } \\
\text { Knowledge } \\
\text { management } \\
\text { Linked data } \\
\text { Ontology } \\
\text { Semantic web }\end{array}$ & $\begin{array}{l}\text { Construction } \\
\text { Infrastructure } \\
\text { Laser scanning } \\
\text { Photogrammetry } \\
\text { Point clouds } \\
\text { Recognition } \\
\text { Reconstruction } \\
\text { visualisation }\end{array}$ & $\begin{array}{l}\text { Architecture } \\
\text { cloud computing } \\
\text { Integration } \\
\text { internet } \\
\text { Internet of things } \\
\text { Management } \\
\text { Technology }\end{array}$ & buildings \\
\hline
\end{tabular}

\subsection{Cluster Analysis}

A cluster represents a set of closely related nodes, and each node is assigned precisely to one group [31]. The clusters, as shown in Figure 2 and Table 2, helped to break down the literature into separate groups that emphasise a particular aspect. Table 2 shows that the maximum number of keywords per cluster was 13, while the minimum was one. The keywords that are listed in the same group appear to show close similarities regarding the research topics. The significant gap between groups, as shown in Figure 2, is 
because of the lack of connections between some topics or due to the lack of relationship between them. A qualitative analysis was considered. However, it cannot cover the total collected literature because of the large volume. Thus, samples of the collected papers were reviewed to give insight into the current research, (Figure 3). Figure 3 summarises the usage of technologies in the project lifecycle. BIM and other technologies have shown the coverage of many resolutions such as energy consumption, clash detection, code compliance, real-time monitoring, and other resolutions. In this section, Clusters 1-4 are discussed.

Cluster 1. In this cluster, the keywords identified were Artificial intelligence, optimisation, performance, prediction, safety, and Machine learning. The massive amount of data generated and the fragmentation of information, as the BIM model develops, have made the decision-making process complex. It has brought about the necessity of utilising technologies from computational areas to help with managing BIM models. BIM cannot be the definitive technological resolution for the construction industry [32]. Shourangiz et al. [32] stated that BIM tools require AI to assess design alternatives. The use of AI and ML can be a solution to several concerns in the construction industry such as performance, prediction, and safety, so that better decision-making can be provided at earlier stages in a project. For example, AI was used for occupancy prediction [33-35], predicting building energy consumption [36], evaluating the performance of sustainable buildings by predicting long-term weather patterns [37], and forecasting construction costs and schedule [38]. However, these studies showed no evident use of BIM. Hence, merging these technologies with BIM can result in a robust decision-making framework for the abovementioned areas of research.

On the other hand, some papers have shown the usage of AI and ML in conjunction with BIM. For instance, information quality inside a facility can be improved by providing an online work order reporting approach [39]. The authors of [40,41] used machine learning to extract injury information from accident reports to predict construction safety. The method used by Tixier et al. [41] can help with identifying risk injuries by detecting crashes in the early stages. Tan [42] stated that merging 3D printing with BIM and AI can be a promising approach to solve 3D printing immaturity problems. McGlinn et al. [43] used $\mathrm{ML}$, ontology, and sensors to put forward a building energy management solution. The use of sensors and ML can help facility managers with the control of a building's energy consumption. Moreover, ML was used to support 3D scanning to identify differences between 3D scans and 3D building models [44]. This shows that ML, ontology, IoT, and LS technologies can complement each other and BIM. Hence, these technologies must be utilised together rather than independently, especially because BIM necessitates the deployment of such technologies to enhance the decision-making process in a project.

Cluster 2. The main keywords found in this cluster were big data, semantic web, ontology, interoperability, and knowledge management. Several relevant reviews were identified on the semantic web and ontology. For instance, Sorensen and Christiansson [45] have reviewed existing ontologies that can help to form a digital link between the virtual models and the physical models. They indicated that ontology could play an essential part in data sharing in the project lifecycle by including different stakeholders [45]. Pauwels et al. [46] examined the expansion and application growth of semantic web technologies in AEC domains for several reasons, such as the necessity of enhancing interoperability problems. Data exchange necessitates the understanding of the industry procedures and also the information needed in these procedures [47]. The study by Pauwels et al. [46] showed that the semantic web has the potential to contribute to applications that involve information from various disciplines. 


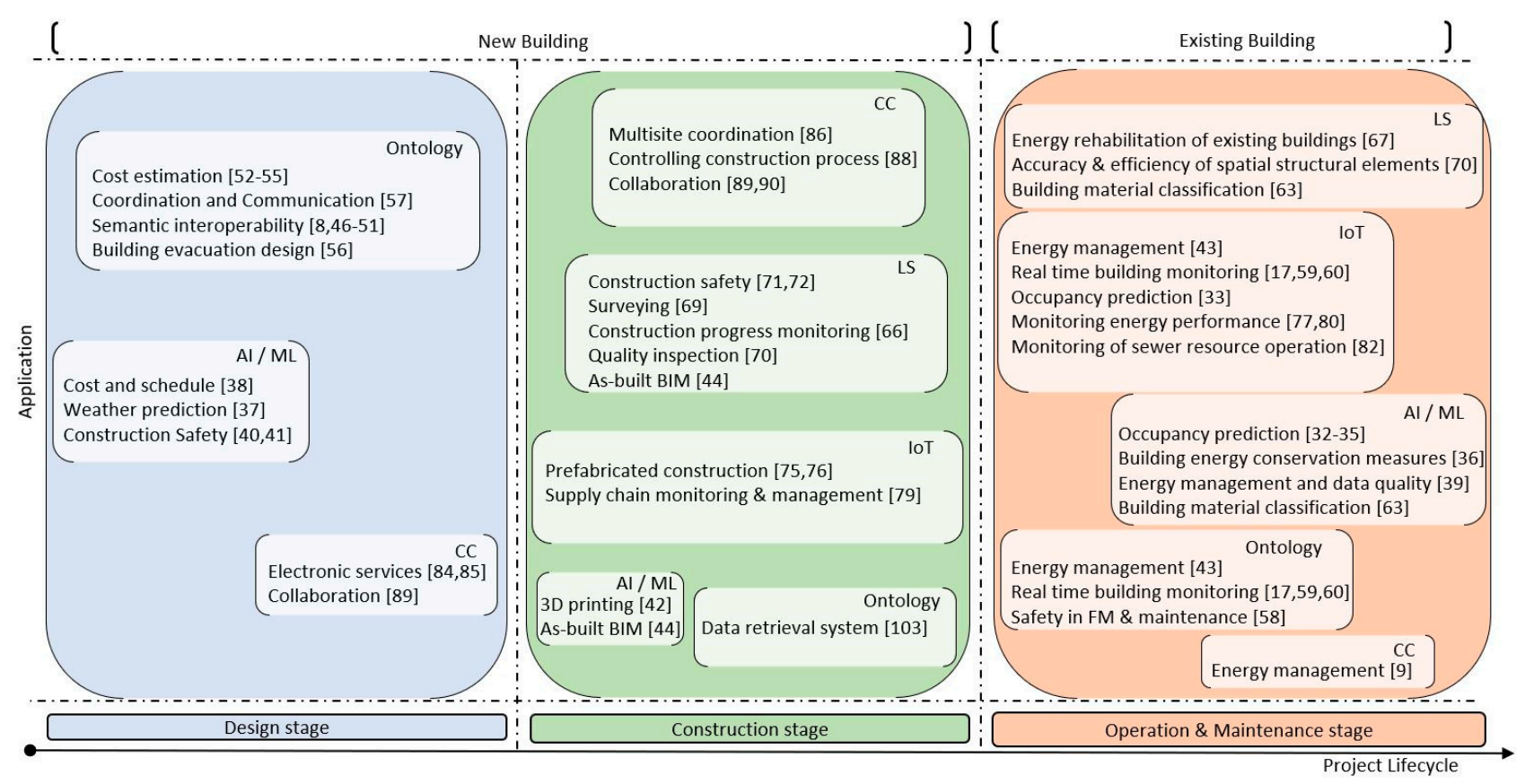

Figure 3. Existing research into technology immersion in the project lifecycle.

Extensive research has been conducted in the area of ontology. For instance, studies have focused on semantic enhancement, information sharing, and online resources retrieval $[8,48,49]$. These studies considered the Industry Foundation Classes (IFC), which is a BIM schema for data exchange. However, although it is a rich schema, Venugopal et al. [8] stated that it is not adequate for realising robust data exchange. They utilised ontology to resolve the doubt that exists in IFC [8]. Furthermore, the study by Karan and Irizarry [50] has shown that ontology is an alternative that can enhance interoperability among the geospatial and BIM domains. Costa and Madrazo [51] applied ontology to establish a connection between BIM models and product catalogues based on IFC. Ontology has been applied in the area of cost estimation [52-55]. The ontology developed by Lee et al. [52] reduced human intervention during the cost estimation process. However, they mention the necessity of revising and updating the ontology with the possibility of engaging experienced engineers to improve the accuracy [52]. Furthermore, ontology has been used for enhancing energy management [43], building evacuation design [56], improving coordination and communication between engineers by recognising conflicts in the BIM design process [57], and safety in facility management and maintenance [58]. The authors of $[59,60]$ developed an ontology to support real-time building information monitoring, where they used ontology and sensors to manage the building data smartly. It shows that these two technologies can complement each other. Furthermore, Zhong et al. [17] proposed an ontology framework to support environmental monitoring and compliance checking among different information systems.

Another term that appeared in this cluster is big data. Lee [61] stated that big data could help companies improve their business operations and services. It includes three main dimensions such as Volume, which represents the size of the available data, Variety that is linked to the heterogeneous data sources, and Velocity, representing the speed at which data is generated [61]. This term was related to several technologies such as DA, AI, IoT and ML. For instance, DA is used to help the decision-making process. It can help to discover and extract important pattern and values from a massive volume of data. Furthermore, Lee [61] mentioned that using this technology can save cost, improve quality, and help make better decisions.

Cluster 3. In this cluster, eight themes appeared, and the keywords identified were laser scanning, construction, reconstruction, and infrastructure. Looking at the review that 
was conducted on LS, Patraucean et al. [62] provided a review of the as-built modelling process to explain the existing challenges of automatic as-built BIM generation. The focus of this review was on the geometric modelling. However, Yuan et al. [63] mentioned that non-geometric information of building elements, including building materials, is becoming an important part of as-is BIM. Furthermore, Wong et al. [64] identified possible research directions concerning digital technology in facility management, where technologies such as 3D LS, point cloud, and IoT were considered. The main findings were the need to improve the interoperability of data from as-designed to as-built data and the necessity to enhance the accuracy of point cloud data [64]. On a similar topic, considering the use of 3D point cloud data in the construction industry, Wang and Kim [65] conducted a thorough review of the application of 3D point cloud data, in which they identified that 3D point cloud data could be useful for construction progress tracking, building performance analysis, construction safety management, and building renovation. They mentioned the importance of collecting semantic information through text mining techniques and integrating it with other sensors, which can be further linked to technology such as virtual reality [65]. These studies reveal the possibility of merging technologies such as AI, ML, and ontology to aid in the use of LS and BIM.

Furthermore, the use of LS cover areas such as construction progress monitoring [66], energy efficiency [67], energy rehabilitation of existing buildings [68], surveying [69], quality inspection [70], and safety rules and regulations check [71,72]. Not forget to mention its application in construction management and facility management [63]. Yuan et al. [63] stated the potential of such technology to enhance building material classification accuracy, noting that only a few studies have adopted this technology for building material classification. They also showed the importance of merging technology, such as ML with LS. Furthermore, Wang [71] stated that research in the area of scaffold safety regulations check is still limited. Consequently, Wang proposed a method to check the safety regulations for scaffold work automatically using 3D point cloud data. On a similar topic, Wang et al. [72] utilised LS technology to inspect safety equipment at excavation sites. It seems that construction safety has caught researchers' attention in recent years, and needs further consideration by the research community. In 2018, Liu et al. [73] proposed a new approach, using LS to improve the accuracy and efficiency of spatial structural elements; it can also be used for structural systems such as buildings, bridges, and culverts. Using LS and BIM can be an essential factor in achieving a complete project visualisation for new and existing buildings. However, Gao et al. [74] noted inconsistency between as-designed BIM and as-built BIM conditions since a building is not continually formed according to the design data indicated.

Cluster 4. Seven themes were shown, and the main keywords identified were the Internet of things and cloud computing. IoT has proven its usefulness in research concerning several construction tasks, e.g., prefabricated construction $[75,76]$, behavioural modelling [77,78], supply chain monitoring and management [79], monitoring energy performance [80,81], and real-time monitoring of sewer resource operation [82]. Moreover, Chen et al. [83] established a warning system for fire rescue using IoT to restore the real-time conditions that can help in creating rescue plans.

On the other hand, several research publications on CC were identified. For instance, $\mathrm{CC}$ was utilised to support augmented reality on a construction site, which showed the possibility of providing a better collaboration among multidisciplinary users [9]. Furthermore, it was used as a decision support tool for energy management [84] and as an integration tool for electronic services [85,86]. Fang et al. [87] developed a system based on BIM and $\mathrm{CC}$ that showed great potential in applications like security control, monitoring tasks, and safety management at construction sites. Petri et al. [88] highlighted the value that a federated cloud could provide to the construction industry. It can be the solution to project management and data sharing between different teams along the project lifecycle [88]. On a similar subject, a semi-structured interview on the use of cloud computing as an integrated platform for BIM applications mentioned the importance of having an integrated system 
over the web [89]. However, the authors concluded that several challenges might arise with this system, such as security and a lack of acceptance by companies. Hence Technologies such as BC, which have been used to solve security issues, can back up such technology and help it to be more adopted in the future. However, most of the research that was conducted on this technology were either conceptual [11], a survey [12], or literature review [13].

Few papers have been found regarding solving security issues within BIM. In 2017, Turk and Klinc [11] presented research on how and when BC can benefit the construction industry. The authors mentioned the need to develop a security model on top of the construction applications. However, this research was conceptual. Zheng et al. [90] mentioned that less effort is made when it comes to information security. They proposed a novel approach where BIM and BC have been used to secure the information. Li et al. [13] conducted a review on $\mathrm{BC}$ technology. They identified several challenges such as "lack of collaboration and information sharing; poor levels of trust between parties; low productivity; late payments; lack of enforcement of regulations; and issues surrounding ownership and intellectual property rights." The authors also stated that using this technology should also be accompanied by improvements across the legal, social and process dimensions. Furthermore, Dakhli et al. [91] reviewed the possibility of using BC in saving cost for a real estate developer.

The identified studies indicated that several technologies could complete each other. Zhi et al. [92] created a monitoring cloud platform by integrating BIM, CC, IoT, and other technologies to control the process of bridge construction by collecting real-time information. This was not the only paper to show the use of more than one technology together; studies have demonstrated the use of CC with virtual reality and augmented reality to enhance workflow productivity and communication among different stakeholders [93,94]. Dibley et al. [60] developed a framework employing ontology to assist in real-time building checking. In 2019, Tang et al. [95] conducted a review on BIM and IoT device integration where they indicated that the BIM and IoT device combination is yet emerging. They mentioned that most of the research on BIM and IoT is not combined with the cloud despite the importance of the cloud in hosting services over the Internet. Moreover, they recommended that future research should focus on real-time data analytics and cloud-based data management solutions [95].

\subsection{Co-Citation Analysis}

The co-citation analysis can be based on three units of analysis: documents cited, sources cited, and authors cited. However, this study focuses on documents cited. In VOSviewer ${ }^{\circledR}$ software, the minimum number of citations of a reference was set to 30 . The results showed that eight out of 20,651 references met this threshold, and four clusters were identified. The identified clusters have articles published between 1993 and 2014. For each group, the document with the highest number of citations is discussed (Table 3).

In Cluster 1, the document with the highest number of citation (48) was [96]. This book offers the technology and processes behind BIM to support architects, engineers, contractors, construction, and facility owners. In Cluster 2, [97], published in Advanced Engineering Informatics, showed the highest number of citations (40). In this paper, Bosché [97] proposed a new approach for the automated tracking of the as-built 3D status of construction sites using LS. One of Bosché's findings was that LS can be used to automate the monitoring of construction projects [97]. However, this can be cost-intensive. Furthermore, the document shown in Cluster 3 was [98], published in Automation in Construction (61 citations). In this paper, Tang et al. [98] surveyed the methods available to automate the process of creating as-built BIMs. They found that most practices are focusing on specific cases, while it is not clear if they can be applied to general situations. They also mentioned that it is "necessary to determine the relationship between the domain-independent requirements for as-built BIM creation with the domain-specific needs for a given problem" [98]. Finally, in Cluster 4, [99], published in Automation in Construction, showed the highest number of citations (40). The findings showed a lack of BIM employment in existing buildings. At the 
same time, great effort is made in relation to new buildings. Topics such as deconstruction and facility management are still not taken seriously in the research field, despite their importance [99]. Volk et al. also mentioned that the release of standards such as Cobie and IFC is the key to future BIM implementation in new and existing buildings [99]. In addition, merging new technologies within the BIM environment can be a promising bridge to BIM employment in existing buildings [99].

Table 3. Co-citation analysis.

\begin{tabular}{|c|c|c|c|c|}
\hline Cluster No & Reference & Category & Year & Theme \\
\hline 1 & [98] & book & 2011 & $\begin{array}{l}\text { Business and organisational problems of } \\
\text { BIM implementation }\end{array}$ \\
\hline 2 & [99] & Journal & 2010 & As-built dimension calculation and control \\
\hline 3 & [100] & Journal-Review & 2010 & $\begin{array}{l}\text { Reviewing the existing techniques to automate the } \\
\text { process of producing as-built BIM }\end{array}$ \\
\hline 4 & [101] & Journal- Review & 2014 & BIM application and examination in existing buildings. \\
\hline
\end{tabular}

\section{Discussion}

\subsection{Technology Dimension for the Future BIM}

BIM has added significant value to the construction industry. It represents a smart digital model to manage different stages of a project more efficiently. The research within this topic has progressed from conceptual to more focused [28]. Despite the benefits of BIM in the construction industry, there are still limitations that prevent BIM from moving forward. It needs to be supported by new technologies to develop a smart BIM that can embrace digital construction by transforming the construction industry into a dynamic environment. The investigation carried out previously in this article has revealed that several technologies can be fused to back up BIM as illustrated in (Table 4), which in turn can add significant value to BIM. This section includes strategic thinking on how several technologies can complement each other and BIM.

Table 4. Existing works on combining various technologies along with BIM.

\begin{tabular}{|c|c|c|c|c|c|c|c|}
\hline \multirow[t]{2}{*}{ Reference } & \multicolumn{7}{|c|}{ Interaction between Different Technologies } \\
\hline & AI/ML/DA & $\mathrm{CC}$ & Ontology & Blockchain & IoTs & LS & BIM \\
\hline [38-41] & $\sqrt{ }$ & & & & & & $\sqrt{ }$ \\
\hline [43] & $\sqrt{ }$ & & $\sqrt{ }$ & & $\sqrt{ }$ & & $\sqrt{ }$ \\
\hline [44] & $\sqrt{ }$ & & & & & $\sqrt{ }$ & $\sqrt{ }$ \\
\hline$[47-54,56,57,100,101]$ & & & $\sqrt{ }$ & & & & $\sqrt{ }$ \\
\hline$[17,59,60]$ & & & $\sqrt{ }$ & & $\sqrt{ }$ & & $\sqrt{ }$ \\
\hline [66-73] & & & & & & $\sqrt{ }$ & $\sqrt{ }$ \\
\hline [80] & & $\sqrt{ }$ & & & $\sqrt{ }$ & & $\sqrt{ }$ \\
\hline [84] & $\sqrt{ }$ & $\sqrt{ }$ & & & $\sqrt{ }$ & & $\sqrt{ }$ \\
\hline [9] & & $\sqrt{ }$ & & & & & $\sqrt{ }$ \\
\hline$[85,86,90]$ & & $\sqrt{ }$ & & $\sqrt{ }$ & & & $\sqrt{ }$ \\
\hline [74-77,81-83], [87] & & $\sqrt{ }$ & & & $\sqrt{ }$ & & $\sqrt{ }$ \\
\hline [93-95] & & $\sqrt{ }$ & & & $\sqrt{ }$ & & $\sqrt{ }$ \\
\hline [91] & & $\sqrt{ }$ & & $\sqrt{ }$ & & & $\sqrt{ }$ \\
\hline
\end{tabular}

As explored earlier, ontology was considered around 2015, whereas research on technologies such as ML and IoT was recognised by the research community in more recent years, which shows the benefits that these technologies can add to the industry. Technologies related to as-built models are highly cited, such as LS, the point cloud, and photogrammetry. Technologies related to prediction and data management show fewer citations, which means they are not entirely taken into consideration yet, possibly because the importance of these technologies is not yet clear. The construction sector needs to understand the prominence of this technology since merging these technologies with BIM can result in a robust decision-making framework. 
Park et al. [100] used an approach to solve construction defect management issues by using ontology. The ontology was used to collect and search for defect information, which can be used by users with no knowledge of defects. ontology is the basis of linked data [101]. It helps engineers to translate the domain knowledge into a format that machines can understand. OWL, which is a web ontology language developed by the World Wide Web Consortium (W3C), has been widely used in the research field. It has different versions such as OWL Lite, OWL-DL (Description Logic), and OWL Full. However, OWL DL has been widely adopted in this research area since it provides an extremely descriptive logic [59].

Furthermore, combining IoT with BIM can be the gateway to establishing a real-time information model, which can reflect the real conditions of a project [78,92], whereby the information gathered from IoT devices is delivered over the Internet [95]. The IoT technology consists of three tiers: a perception tier (equipment), a network tier (Internet and Bluetooth), and an application tier (interface) [82]. Merging this technology can expand the use of data [81]. However, Tao et al. [6] stated that managing the massive amount of information generated by sensors is quite challenging, especially when it comes to sharing this information among various stakeholders and systems.

Technology such as CC is essential with IoT technology since it delivers an enhanced service on the Internet [88], which permits users to access information remotely. In the United States (U.S.), the National Institute of Standards and Technology (NIST), which is a non-regulatory federal agency within the U.S. Department of Commerce that is accountable for developing standards and guidelines, describes CC as "a model for enabling ubiquitous, convenient, on-demand network access to a shared pool of configurable computing resources (e.g., networks, servers, storage, applications, and services) that can be rapidly provisioned and released with minimal management effort or service provider interaction" [102]. CC presents various services such as software as a service (SaaS), platform as a service (PaaS), and infrastructure as a service (IaaS) [72,81]. Merging this technology with BIM can be an essential step with great benefits. For instance, it can enhance integration, collaboration, and interoperability between different users and across the different stages of a project lifecycle. The use of CC with BIM is not a new research area. However, Fang et al. [87] stated that the construction industry does not take enough advantage of CC. It needs further exploration to achieve a cohesive collaboration environment that can bring different stakeholders together.

Furthermore, IoT technology can be enabled by big data techniques [95] such as DA, AI and ML. Tan [42] defines AI as "a technology that develops theories, methods, techniques, and applications to extend people's intelligence." In order to have a smart building, real-time occupancy prediction and energy management are essential factors that need to be controlled [103]. ML, which is an application of AI, has good performance at occupancy prediction so can be used to manage energy more efficiently. However, most of the research showed no link to BIM yet. AI and BIM complement each other not only in the design stage but also in different stages of the project. For instance, combining AI with BIM can help with schedule planning in the construction stage, and could enable and automate the decision-making process in the construction industry [42]. However, most of these technologies are not fully embraced by the construction industry yet and require further research.

Previous studies on LS showed the importance of using this technology. However, it was not linked to the concepts of BIM, whereas most recent studies showed the adoption of BIM. BIM can be represented as the data repositories for as-built data [74]. LS and BIM technologies play a significant role in enhancing the details of a model. Bosché and Guenet [70] stated that the implementation of these technologies in the construction industry is rising quickly. LS can be used in process tracking and generating as-built models. However, Bosché and Guenet identified limitations within LS technology such as a lack of accuracy and manual data processing [70]. 
Using all these technologies can influence the use of BIM in the construction industry. However, security would be required as the size and complexity of the data increase. The data collected in this research have shown a lack of papers when it comes to security within BIM. This was confirmed by the findings of Zheng et al. [90], who mentioned that less effort is made when it comes to information security. BC is a technology that has been used to solve security issues within the BIM environment. However, the research on this topic is still in the preliminary stages. Most of the research that was conducted on this topic were either conceptual [11], a survey [12], or a literature review [13]. Hence, this topic needs further exploration from the research community to show how to merge and implement such a technology to overcome security issues within BIM.

\subsection{Technology Fusion Supporting BIM Development}

The complexity assets force the adoption of new technologies or tools to manage all the information [18]. BIM is not a short-term concept; it fundamentally underlies the digitalisation of the construction industry. It has been used to assist with managing data across the building lifecycle. However, a weak information integration and management approach can limit the ability to leverage a smart BIM environment. In this study, it has been shown that one type of technology alone cannot solve particular issues entirely. Current technologies have been utilised independently and not as a coherent system. A collective approach applying technologies such as AI, CC, Ontology, BC, DA, IoT, LS and ML to provide a dynamic BIM environment has not been proposed yet. The purpose of this section is to underline the functionalities that should be included to achieve the full potential of BIM. By looking at the studies concerning these technologies and BIM from 2010 to 2019, we identify that each functionality required a specific type of technology. Therefore, the authors indicated a technology fusion to support BIM development (Figure 4) as follows:

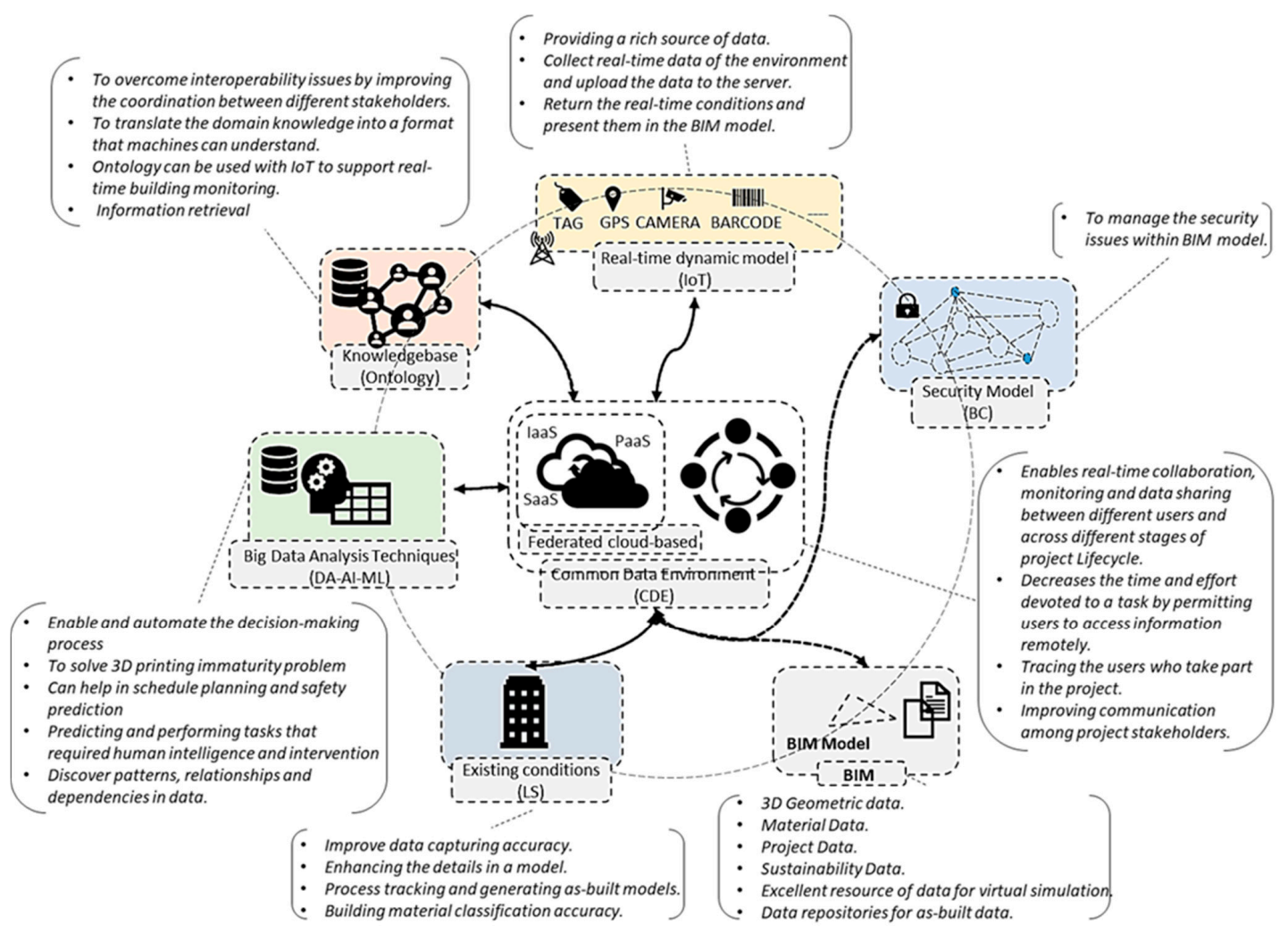

Figure 4. Technology fusion supporting future BIM development. 
- Common data environment (CDE). Having sophisticated building design requirements necessitates a better way of sharing information throughout the building life cycle, which requires data to be exchanged among different stakeholders throughout the entire process. An environment where all information is shared centrally can deliver smooth decision-making processes and promote collaboration among different stakeholders. This points to the need for a federated cloud-based platform to transfer all this information. Connecting to the cloud decreases the time and effort devoted to a task. Furthermore, it can trace the users who take part in the project by displaying their actions in the project. The release of standards such as IFC, and the emergence of new technologies within BIM, can be a promising step toward a shared data environment and BIM engagement in diverse stages of the building lifecycle [99]. Technologies will be connected to a cloud-based platform, which forms a federated cloud-based system that allows for real-time data synchronisations among different stakeholders throughout the entire building lifecycle to boost collaboration, monitoring, and data sharing.

- Real-time dynamic model. IoT technology, which makes a significant contribution to the concept of the digital twin, is one of the technologies that proved its worth in providing a productive environment for data for BIM models. IoT can be a tool to nourish a system with various types of real-time information. The concept of the IoT is based on using sensors or other devices such as Tags, GPS, Cameras and barcodes as integrated tools by connecting them to the Internet [104]. For instance, connecting the IoT to the cloud can be a means of network bonding since CC can be used as a database, cloud storage, server, and high-performance computing device [105] that can enable real-time collaboration. Likewise, the data collected from sensors can represent the input to technologies such as DA, AI and ML that can be used to train the collected data and help transfer them into knowledge, which will improve the decision-making process in existing and future projects. Using IoT technology will require following specific guidelines, standards, or rules while exchanging or sharing information, which can smoothen information exchange among different stakeholders [106]. Standards such as IFC can help with the information exchange. However, Zhong et al. [17] stated that "Although a new entity IFCSensor has been added to the latest release of IFC, it still needs to be designed for building environmental monitoring by adding related attributes."

- Big Data Analysis Techniques. The drawback of using IoT technology alone is that the more data that are generated, the harder the process of applying and managing the data [107]. It is crucial to think of a smart way to manage the data. The success of IoT technology relies on connecting information to buildings and also embedding intelligence, in which big data analytics plays a significant role by converting information into knowledge so that it can be reused to improve the decision-making process and provide a more consistent model. However, using such technology requires significant programming knowledge. The realisation of a digital twin is linked to the extent of human intervention. The less human intervention is needed, the better the digital twin will perform. Merging technologies such as DA, AI and ML with BIM by taking advantage of IoT technology as input can enhance and automate decision-making and management during a project. ML can play a vital role in safety prediction, building material classification and energy consumption. It also reinforces the idea of the lesson learned, which is based on enhancing new projects by learning from past mistakes, since repeating the same mistakes in a large project can be expensive and time-consuming.

- Knowledgebase. Ontology has the potential to improve interoperability issues within BIM models by implementing domain knowledge into the BIM model, which can provide semantic enrichment of the BIM model. It helps to translate the domain knowledge into a format that machines can understand. Ontology can be the solution to 
overcome the concerns about how BIM can handle various semantic information. Furthermore, ontology can be used with the IoT to support real-time building monitoring.

- Existing conditions. Using BIM in existing buildings is still accompanied by some challenges. LS can be an essential tool for covering the missing part of BIM for existing buildings by creating models out of existing conditions. Furthermore, it can be used for quality inspection, construction progress tracking, building performance analysis, building material classification, and construction safety management. It can be advanced with the use of IoT to provide real-time data. Moreover, the use of LS with 3D printing has shown its potential in building renovation [108].

- Security Model. A security model is needed to manage security issues within the BIM model, which can help with ownership and accessibility issues during project development by preventing unauthorised access to information and the technologies involved. The ideal way to build this layer is to have it separate from the system rather than integrated within a specific stage or task [11]. BC is one of the technologies that has been used to suppress security issues within BIM. It can be divided into three types such as public BC, private $\mathrm{BC}$, and consortium BC, where each type is used to fulfil a specific purpose [90].

\section{Conclusions}

This paper adopted a science mapping approach to evaluate how selected cuttingedge technologies can contribute to and shape BIM from a technical perspective. A fivestage method was used to search, filter, and review publications to aid in the strategic thinking about how several technologies can complement each other and BIM. A total of 679 publications, including articles, proceedings papers, and reviews published since 2010 were selected as the literature sample from the WoS database. An analysis of co-occurrence terms, and co-citation was provided, and a critical review was performed.

From the literature, it can be seen that adopting new technologies such as ontology, $\mathrm{AI}$, and ML, and using new technologies such as BC can help with solving the existing limitations of BIM applications. However, it has been concluded that one type of technology cannot completely solve particular issues. Current technologies have been utilised independently and not as a coherent system. A collective approach to applying these technologies to provide a dynamic BIM environment has not been proposed yet. Thus, it is expected that the possibility of having more than one technology working together with BIM is quite close to realisation, and this is an important area of research. In response to these findings, a corresponding technology fusion to support BIM development is indicated.

The integration of advanced technologies with BIM into one system has become a hot research topic. Merging these technologies and taking advantage of their power can be an excellent opportunity to build a support system that can level up BIM and the decisionmaking process across the building lifecycle. However, it may take several years to achieve that. This paper is not meant to be exclusive. There are many technologies, concepts, and ideas that can be added to help BIM reach its full potential but are not covered in this study. Furthermore, the analysis was based on the dataset retrieved from WoS and only included literature in English. In addition to the quantitative analysis, a qualitative study was considered, which cannot cover all the literature collected because of the large volume. Samples of the collected papers were reviewed to give insight into the current research. Thus, this study may not reflect the entire BIM literature within those topics.

Author Contributions: Conceptualization, H.L. and S.L.; Methodology, A.K. and H.L; software, A.K.; formal analysis, A.K.; investigation, A.K.; formal discussion, A.K., H.L., G.R. and S.L.; writingoriginal draft preparation, A.K.; writing-review and editing, G.R.; supervision, H.L. All authors have read and agreed to the published version of the manuscript.

Funding: This research is partially supported by industry funding from CCCC Second Harbor Consultants Co., Ltd. 
Acknowledgments: The authors would like to acknowledge the support provided by Cardiff University, UK, and CCCC Second Harbour Engineering Company Ltd., China.

Conflicts of Interest: The authors declare no conflict of interest in the writing of the manuscript.

\section{References}

1. Steel, J.; Drogemuller, R.; Toth, B. Model interoperability in building information modelling. Softw. Syst. Model. 2012, 11, 99-109. [CrossRef]

2. Aziz, N.D.; Nawawi, A.H.; Ariff, N.R.M. Building Information Modelling (BIM) in Facilities Management: Opportunities to be Considered by Facility Managers. Procedia-Soc. Behav. Sci. 2016, 234, 353-362. [CrossRef]

3. Eadie, R.; Browne, M.; Odeyinka, H.; McKeown, C.; McNiff, S. BIM implementation throughout the UK construction project lifecycle: An analysis. Autom. Constr. 2013, 36, 145-151. [CrossRef]

4. Trentesaux, D.; Karnouskos, S. Service Oriented, Holonic and Multi-agent Manufacturing Systems for Industry of the Future. Springer 2020, 853, 1-18. [CrossRef]

5. Modelling, B.I.; Plan, S. Digital Built Britain Level 3 Building Information Modelling_Strategic Plan; HM Government: London, UK, 2015; pp. 1-47.

6. Tao, F.; Cheng, J.; Qi, Q.; Zhang, M.; Zhang, H.; Sui, F. Digital twin-driven product design, manufacturing and service with big data. Int. J. Adv. Manuf. Technol. 2018, 94, 3563-3576. [CrossRef]

7. Succar, B. Automation in Construction Building information modelling framework: A research and delivery foundation for industry stakeholders. Autom. Constr. 2009, 18, 357-375. [CrossRef]

8. Venugopal, M.; Eastman, C.M.; Teizer, J. An ontology-based analysis of the industry foundation class schema for building information model exchanges. Adv. Eng. Inform. 2015, 29, 940-957. [CrossRef]

9. Jiao, Y.; Zhang, S.; Li, Y.; Wang, Y.; Yang, B. Automation in Construction Towards cloud Augmented Reality for construction application by BIM and SNS integration. Autom. Constr. 2013, 33, 37-47. [CrossRef]

10. Bhatija, V.P.; Thomas, N.; Dawood, N. A Preliminary Approach towards Integrating Knowledge Management with Building Information Modeling (KBIM) for the Construction Industry. Int. J. Innov. Manag. Technol. 2017, 8, 64-70. [CrossRef]

11. Turk, Ž.; Klinc, R. Potentials of Blockchain Technology for Construction Management. Procedia Eng. 2017, 196, 638-645. [CrossRef]

12. Nawari, O.; Nawari, K.B.; Ravindran, S. Blockchain technology and BIM process: Review and potential applications. J. Inf. Technol. Constr. 2019, 24, 209-238.

13. Li, J.; Greenwood, D.; Kassem, M. Blockchain in the built environment and construction industry: A systematic review, conceptual models and practical use cases. Autom. Constr. 2019, 102, 288-307. [CrossRef]

14. Sun, C.; Jiang, S.; Skibniewski, M.J.; Man, Q.; Shen, L. A literature review of the factors limiting the application of BIM in the construction industry. Technol. Econ. Dev. Econ. 2017, 23, 764-779. [CrossRef]

15. Chi, H.L.; Wang, X.; Jiao, Y. BIM-Enabled Structural Design: Impacts and Future Developments in Structural Modelling, Analysis and Optimisation Processes. Arch. Comput. Methods Eng. 2015, 22, 135-151. [CrossRef]

16. Rokooei, S. Building Information Modeling in Project Management: Necessities, Challenges and Outcomes. Procedia-Soc. Behav. Sci. 2015, 210, 87-95. [CrossRef]

17. Zhong, B.; Gan, C.; Luo, H.; Xing, X. Ontology-based framework for building environmental monitoring and compliance checking under BIM environment. Build. Environ. 2018, 141, 127-142. [CrossRef]

18. Arthur, S.; Li, H.; Lark, R. The Emulation and Simulation of Internet of Things Devices for Building Information Modelling (BIM). In Workshop of the European Group for Intelligent Computing in Engineering; Springer: Cham, Switzerland, 2018. [CrossRef]

19. Nguyen, T.H.; Kim, J.L. Building code compliance checking using BIM technology. In Proceedings of the 2011 Winter Simulation Conference (wsc), Phoenix, AZ, USA, 11-14 December 2011; pp. 3395-3400. [CrossRef]

20. Grilo, A.; Jardim-Goncalves, R. Value proposition on interoperability of BIM and collaborative working environments. Autom. Constr. 2010, 19, 522-530. [CrossRef]

21. Oraee, M.; Hosseini, M.R.; Palliyaguru, R.; Tivendale, L. Bibliometric Analysis of Published Studies in ASCE Construction Research Congress, USA. In Proceedings of the Construction Research Congress 2018: Sustainable Design and Construction and Education- Selected Papers from the Construction Research Congress, New Orleans, LA, USA, 2-4 April 2018; pp. 13-23. [CrossRef]

22. Zou, X.; Yue, W.L.; Vu, H. Le Visualization and analysis of mapping knowledge domain of road safety studies. Accid. Anal. Prev. 2018, 118, 131-145. [CrossRef]

23. Li, X.; Wu, P.; Shen, G.Q.; Wang, X.; Teng, Y. Mapping the knowledge domains of Building Information Modeling (BIM): A bibliometric approach. Autom. Constr. 2017, 84, 195-206. [CrossRef]

24. He, Q.; Wang, G.; Luo, L.; Shi, Q.; Xie, J.; Meng, X. Mapping the managerial areas of Building Information Modeling (BIM) using scientometric analysis. Int. J. Proj. Manag. 2017, 35, 670-685. [CrossRef]

25. Oraee, M.; Hosseini, M.R.; Papadonikolaki, E. ScienceDirect Collaboration in BIM-based construction networks: A bibliometricqualitative literature review. Int. J. Proj. Manag. 2017, 35, 1288-1301. [CrossRef]

26. Oraee, M.; Hosseini, M.R.; Palliyaguru, R.; Tivendale, L. Construction Research Congress 2018. Proc. Constr. Res. Congr. 2018, 2018, 148-157. [CrossRef]

27. Zhao, X. A scientometric review of global BIM research: Analysis and visualization. Autom. Constr. 2017, 80, 37-47. [CrossRef] 
28. Santos, R.; Costa, A.A.; Grilo, A. Automation in Construction Bibliometric analysis and review of Building Information Modelling literature published between 2005 and 2015. Autom. Constr. 2017, 80, 118-136. [CrossRef]

29. Hosseini, M.R.; Asce, M.; Maghrebi, M.; Akbarnezhad, A.; Martek, I.; Arashpour, M. Analysis of Citation Networks in Building Information Modeling Research. J. Constr. Eng. Manag. 2018, 144, 04018064. [CrossRef]

30. VOSviewer-Visualizing Scientific Landscapes. Available online: https://www.vosviewer.com/ (accessed on 11 January 2021).

31. Eck, V.; Rousseau, R. Visualizing Bibliometric Networks. In Measuring Scholarly Impact: Methods and Practice; Ding, Y., Rousseau, R., Wolfram, D., Eds.; Springer: Berlin/Heidelberg, Germany, 2014; pp. 285-320, ISBN 9783319103778.

32. Shourangiz, E.; Mohamad, M.; Hassanabadi, M.; Banihashemi, S.; Bakhtiari, M.; Torabi, M. Flexibility of BIM towards Design Change. In Proceedings of the 2nd International Conference on Construction and Project Management, Singapore, 16-18 September 2011; IACSIT Press: Singapore, 2011; Volume 15, pp. 79-83.

33. Chen, Z.; Masood, M.K.; Soh, Y.C. A fusion framework for occupancy estimation in office buildings based on environmental sensor data. Energy Build. 2016, 133, 790-798. [CrossRef]

34. Ryu, S.H.; Moon, H.J. Development of an occupancy prediction model using indoor environmental data based on machine learning techniques. Build. Environ. 2016, 107, 1-9. [CrossRef]

35. Jiang, C.; Masood, M.K.; Soh, Y.C.; Li, H. Indoor occupancy estimation from carbon dioxide concentration. Energy Build. 2016, 131, 132-141. [CrossRef]

36. Marasco, D.E.; Kontokosta, C.E. Applications of machine learning methods to identifying and predicting building retrofit opportunities. Energy Build. 2016, 128, 431-441. [CrossRef]

37. Chakraborty, D.; Elzarka, H.; Bhatnagar, R. Generation of accurate weather files using a hybrid machine learning methodology for design and analysis of sustainable and resilient buildings. Sustain. Cities Soc. 2016, 24, 33-41. [CrossRef]

38. Wang, Y.R.; Yu, C.Y.; Chan, H.H. Predicting construction cost and schedule success using artificial neural networks ensemble and support vector machines classification models. Int. J. Proj. Manag. 2012, 30, 470-478. [CrossRef]

39. McArthur, J.J.; Shahbazi, N.; Fok, R.; Raghubar, C.; Bortoluzzi, B.; An, A. Machine learning and BIM visualization for maintenance issue classification and enhanced data collection. Adv. Eng. Inform. 2018, 38, 101-112. [CrossRef]

40. Tixier, A.J.P.; Hallowell, M.R.; Rajagopalan, B.; Bowman, D. Application of machine learning to construction injury prediction. Autom. Constr. 2016, 69, 102-114. [CrossRef]

41. Tixier, A.J.P.; Hallowell, M.R.; Rajagopalan, B.; Bowman, D. Construction Safety Clash Detection: Identifying Safety Incompatibilities among Fundamental Attributes using Data Mining. Autom. Constr. 2017, 74, 39-54. [CrossRef]

42. Tan, K. The Framework of Combining Artificial Intelligence and Construction 3D Printing in Civil Engineering. MATEC Web Conf. 2018, 206, 01008. [CrossRef]

43. McGlinn, K.; Yuce, B.; Wicaksono, H.; Howell, S.; Rezgui, Y. Usability evaluation of a web-based tool for supporting holistic building energy management. Autom. Constr. 2017, 84, 154-165. [CrossRef]

44. Tamke, M.; Zwierzycki, M.; Evers, H.L.; Ochmann, S.; Vock, R.; Wessel, R. Tracking Changes in Buildings over Time-Fully Automated Reconstruction and Difference Detection of 3d Scan and BIM files. In Proceedings of the 34th eCAADe Conference, Oulu, Finland, 22-26 August 2016; Volume 2, pp. 643-651.

45. Sørensen, K.B.; Christiansson, P.; Svidt, K. Ontologies to support RFID-based link between virtual models and construction components. Comput. Civ. Infrastruct. Eng. 2010, 25, 285-302. [CrossRef]

46. Pauwels, P.; Zhang, S.; Lee, Y.C. Semantic web technologies in AEC industry: A literature overview. Autom. Constr. 2017, 73, 145-165. [CrossRef]

47. Venugopal, M.; Eastman, C.M.; Sacks, R.; Teizer, J. Semantics of model views for information exchanges using the industry foundation class schema. Adv. Eng. Inform. 2012. [CrossRef]

48. Gao, G.; Liu, Y.S.; Wang, M.; Gu, M.; Yong, J.H. A query expansion method for retrieving online BIM resources based on Industry Foundation Classes. Autom. Constr. 2015, 56, 14-25. [CrossRef]

49. König, M.; Dirnbek, J.; Stankovski, V. Architecture of an open knowledge base for sustainable buildings based on Linked Data technologies. Autom. Constr. 2013, 35, 542-550. [CrossRef]

50. Karan, E.P.; Irizarry, J. Extending BIM interoperability to preconstruction operations using geospatial analyses and semantic web services. Autom. Constr. 2015, 53, 1-12. [CrossRef]

51. Costa, G.; Madrazo, L. Connecting building component catalogues with BIM models using semantic technologies: An application for precast concrete components. Autom. Constr. 2015, 57, 239-248. [CrossRef]

52. Lee, S.K.; Kim, K.R.; Yu, J.H. BIM and ontology-based approach for building cost estimation. Autom. Constr. 2014, 41, 96-105. [CrossRef]

53. Niknam, M.; Karshenas, S. A shared ontology approach to semantic representation of BIM data. Autom. Constr. 2017, 80, 22-36. [CrossRef]

54. Abanda, F.H.; Kamsu-Foguem, B.; Tah, J.H.M. BIM-New rules of measurement ontology for construction cost estimation. Eng. Sci. Technol. Int. J. 2017, 20, 443-459. [CrossRef]

55. Liu, H.; Lu, M.; Al-Hussein, M. Ontology-based semantic approach for construction-oriented quantity take-off from BIM models in the light-frame building industry. Adv. Eng. Inform. 2016, 30, 190-207. [CrossRef]

56. Boje, C.; Li, H. Advanced Engineering Informatics Crowd simulation-based knowledge mining supporting building evacuation design. Adv. Eng. Inform. 2018, 37, 103-118. [CrossRef] 
57. Liu, Y. Consistency checking based on ontology of design information. Appl. Mech. Mater. 2013, 438-439, 1992-1997. [CrossRef]

58. Wetzel, E.M.; Thabet, W.Y. The use of a BIM-based framework to support safe facility management processes. Autom. Constr. 2015, 60, 12-24. [CrossRef]

59. Dibley, M.J.; Li, H.; Miles, J.C.; Rezgui, Y. Towards intelligent agent based software for building related decision support. Adv. Eng. Inform. 2011, 25, 311-329. [CrossRef]

60. Dibley, M.; Li, H.; Rezgui, Y.; Miles, J. An ontology framework for intelligent sensor-based building monitoring. Autom. Constr. 2012, 28, 1-14. [CrossRef]

61. Lee, I. Big data: Dimensions, evolution, impacts, and challenges. Bus. Horiz. 2017, 60, 293-303. [CrossRef]

62. Pətrəucean, V.; Armeni, I.; Nahangi, M.; Yeung, J.; Brilakis, I.; Haas, C. State of research in automatic as-built modelling. Adv. Eng. Inform. 2015, 29, 162-171. [CrossRef]

63. Yuan, L.; Guo, J.; Wang, Q. Automatic classification of common building materials from 3D terrestrial laser scan data. Autom. Constr. 2020, 110, 103017. [CrossRef]

64. Wong, J.K.W.; Ge, J.; He, S.X. Digitisation in facilities management: A literature review and future research directions. Autom. Constr. 2018, 92, 312-326. [CrossRef]

65. Wang, Q.; Kim, M.K. Applications of 3D point cloud data in the construction industry: A fifteen-year review from 2004 to 2018. Adv. Eng. Inform. 2019, 39, 306-319. [CrossRef]

66. Han, K.; Degol, J.; Golparvar-Fard, M. Geometry- and Appearance-Based Reasoning of Construction Progress Monitoring. J. Constr. Eng. Manag. 2018, 144, 1-12. [CrossRef]

67. Wang, C.; Cho, Y.K. Performance Evaluation of Automatically Generated BIM from Laser Scanner Data for Sustainability Analyses. Procedia Eng. 2015, 118, 918-925. [CrossRef]

68. Lagüela, S.; Díaz-Vilariño, L.; Martínez, J.; Armesto, J. Automatic thermographic and RGB texture of as-built BIM for energy rehabilitation purposes. Autom. Constr. 2013, 31, 230-240. [CrossRef]

69. Mill, T.; Alt, A.; Liias, R. Combined 3D Building Surveying Techniques-Terrestrial Laser Scanning (Tls) and Total Station Surveying for Bim Data Management Purposes. J. Civ. Eng. Manag. 2013, 19, S23-S32. [CrossRef]

70. Bosché, F.; Guenet, E. Automating surface flatness control using terrestrial laser scanning and building information models. Autom. Constr. 2014, 44, 212-226. [CrossRef]

71. Wang, Q. Automatic checks from 3D point cloud data for safety regulation compliance for scaffold work platforms. Autom. Constr. 2019, 104, 38-51. [CrossRef]

72. Wang, J.; Zhang, S.; Teizer, J. Geotechnical and safety protective equipment planning using range point cloud data and rule checking in building information modeling. Autom. Constr. 2015, 49, 250-261. [CrossRef]

73. Liu, J.; Zhang, Q.; Wu, J.; Zhao, Y. Dimensional accuracy and structural performance assessment of spatial structure components using 3D laser scanning. Autom. Constr. 2018, 96, 324-336. [CrossRef]

74. Gao, T.; Akinci, B.; Ergan, S.; Garrett, J. An approach to combine progressively captured point clouds for BIM update. Adv. Eng. Inform. 2015, 29, 1001-1012. [CrossRef]

75. Li, C.Z.; Xue, F.; Li, X.; Hong, J.; Shen, G.Q. An Internet of Things-enabled BIM platform for on-site assembly services in prefabricated construction. Autom. Constr. 2018, 89, 146-161. [CrossRef]

76. Zhong, R.Y.; Peng, Y.; Xue, F.; Fang, J.; Zou, W.; Luo, H.; Thomas Ng, S.; Lu, W.; Shen, G.Q.P.; Huang, G.Q. Prefabricated construction enabled by the Internet-of-Things. Autom. Constr. 2017, 76, 59-70. [CrossRef]

77. Pasini, D. Connecting BIM and IoT for addressing user awareness toward energy savings. J. Struct. Integr. Maint. 2018, 3, 243-253. [CrossRef]

78. Ciribini, A.L.C.; Pasini, D.; Tagliabue, L.C.; Manfren, M.; Daniotti, B.; Rinaldi, S.; De Angelis, E. Tracking Users' Behaviors through Real-time Information in BIMs: Workflow for Interconnection in the Brescia Smart Campus Demonstrator. Procedia Eng. 2017, 180, 1484-1494. [CrossRef]

79. Dave, B.; Kubler, S.; Främling, K.; Koskela, L. Opportunities for enhanced lean construction management using Internet of Things standards. Autom. Constr. 2016, 61, 86-97. [CrossRef]

80. Wu, W.; Li, W.; Law, D.; Na, W. Improving Data Center Energy Efficiency Using a Cyber-physical Systems Approach: Integration of Building Information Modeling and Wireless Sensor Networks. Procedia Eng. 2015, 118, 1266-1273. [CrossRef]

81. Kang, K.; Lin, J.; Zhang, J. BIM- and IoT-based monitoring framework for building performance management. J. Struct. Integr. Maint. 2018, 3, 254-261. [CrossRef]

82. Edmondson, V.; Cerny, M.; Lim, M.; Gledson, B.; Lockley, S.; Woodward, J. A smart sewer asset information model to enable an 'Internet of Things' for operational wastewater management. Autom. Constr. 2018, 91, 193-205. [CrossRef]

83. Chen, X.S.; Liu, C.C.; Wu, I.C. A BIM-based visualization and warning system for fire rescue. Adv. Eng. Inform. 2018, 37, 42-53. [CrossRef]

84. Cho, Y.K.; Li, H.; Park, J.; Zheng, K. A Framework for Cloud-based Energy Evaluation and Management for Sustainable Decision Support in the Built Environments. Procedia Eng. 2015, 118, 442-448. [CrossRef]

85. Grilo, A.; Jardim-Goncalves, R. Challenging electronic procurement in the AEC sector: A BIM-based integrated perspective. Autom. Constr. 2011, 20, 107-114. [CrossRef]

86. Jardim-Goncalves, R.; Grilo, A. SOA4BIM: Putting the building and construction industry in the Single European Information Space. Autom. Constr. 2010, 19, 388-397. [CrossRef] 
87. Fang, Y.; Cho, Y.K.; Zhang, S.; Perez, E. Case Study of BIM and Cloud-Enabled Real-Time RFID Indoor Localization for Construction Management Applications. J. Constr. Eng. Manag. 2016, 142, 05016003. [CrossRef]

88. Petri, I.; Beach, T.; Rana, O.F.; Rezgui, Y. Coordinating multi-site construction projects using federated clouds. Autom. Constr. 2017, 83, 273-284. [CrossRef]

89. Redmond, A.; Hore, A.; Alshawi, M.; West, R. Exploring how information exchanges can be enhanced through Cloud BIM. Autom. Constr. 2012, 24, 175-183. [CrossRef]

90. Zheng, R.; Jiang, J.; Hao, X.; Ren, W.; Xiong, F.; Ren, Y. BcBIM: A Blockchain-Based Big Data Model for BIM Modification Audit and Provenance in Mobile Cloud. Math. Probl. Eng. 2019, 2019. [CrossRef]

91. Dakhli, Z.; Lafhaj, Z.; Mossman, A. The Potential of Blockchain in Building Construction. Buildings 2019, 9, 77. [CrossRef]

92. Zhi, P.; Shi, T.; Wang, W.; Wang, H. Application Research on Monitoring Cloud Platform of Bridge Construction Based on BIM. In Proceedings of the 2017 6th International Conference on Energy, Environment and Sustainable Development (ICEESD 2017), Advances in Engineering Research, Zhuhai, China, 11-12 March 2017; Volume 129, pp. 67-72. [CrossRef]

93. Du, J.; Zou, Z.; Shi, Y.; Zhao, D. Simultaneous Data Exchange between BIM and VR for Collaborative Decision Making. Congr. Comput. Civ. Eng. Proc. 2017, 2017, 1-8. [CrossRef]

94. Du, J.; Shi, Y.; Zou, Z.; Zhao, D. CoVR: Cloud-Based Multiuser Virtual Reality Headset System for Project Communication of Remote Users. J. Constr. Eng. Manag. 2018, 144, 1-19. [CrossRef]

95. Tang, S.; Shelden, D.R.; Eastman, C.M.; Pishdad-Bozorgi, P.; Gao, X. A review of building information modeling (BIM) and the internet of things (IoT) devices integration: Present status and future trends. Autom. Constr. 2019, 101, 127-139. [CrossRef]

96. Dein, S. Book Review. Anthropol. Med. 2013, 20, 326-327. [CrossRef]

97. Bosché, F. Automated recognition of 3D CAD model objects in laser scans and calculation of as-built dimensions for dimensional compliance control in construction. Adv. Eng. Inform. 2010, 24, 107-118. [CrossRef]

98. Tang, P.; Huber, D.; Akinci, B.; Lipman, R.; Lytle, A. Automatic reconstruction of as-built building information models from laser-scanned point clouds: A review of related techniques. Autom. Constr. 2010, 19, 829-843. [CrossRef]

99. Volk, R.; Stengel, J.; Schultmann, F. Automation in Construction Building Information Modeling (BIM) for existing buildingsLiterature review and future needs. Autom. Constr. 2014, 38, 109-127. [CrossRef]

100. Park, C.S.; Lee, D.Y.; Kwon, O.S.; Wang, X. A framework for proactive construction defect management using BIM, augmented reality and ontology-based data collection template. Autom. Constr. 2013, 33, 61-71. [CrossRef]

101. Li, Y.; García-Castro, R.; Mihindukulasooriya, N.; O’Donnell, J.; Vega-Sánchez, S. Enhancing energy management at district and building levels via an EM-KPI ontology. Autom. Constr. 2019, 99, 152-167. [CrossRef]

102. Mell, P.; Grance, T. The NIST-National Institute of Standars and Technology- Definition of Cloud Computing. NIST Spec. Publ. 2011, 7, 145-800.

103. Li, Z.; Dong, B. Short term predictions of occupancy in commercial buildings-Performance analysis for stochastic models and machine learning approaches. Energy Build. 2018, 158, 268-281. [CrossRef]

104. Chen, S.; Xu, H.; Liu, D.; Hu, B.; Wang, H. A vision of IoT: Applications, challenges, and opportunities with China Perspective. IEEE Internet Things J. 2014, 1, 349-359. [CrossRef]

105. Arthur, S.; Li, H.; Lark, R. A Collaborative Unified Computing Platform for Building Information Modelling (BIM). In Working Conference on Virtual Enterprises; Springer: Cham, Switzerland, 2017. [CrossRef]

106. Dave, B.; Buda, A.; Nurminen, A.; Främling, K. A framework for integrating BIM and IoT through open standards. Autom. Constr. 2018, 95, 35-45. [CrossRef]

107. Akanmu, A.; Anumba, C.J. Cyber-physical systems integration of building information models and the physical construction. Eng. Constr. Archit. Manag. 2015, 22, 516-535. [CrossRef]

108. Xu, J.; Ding, L.; Love, P.E.D. Automation in Construction Digital reproduction of historical building ornamental components: From 3D scanning to 3D printing. Autom. Constr. 2017, 76, 85-96. [CrossRef] 